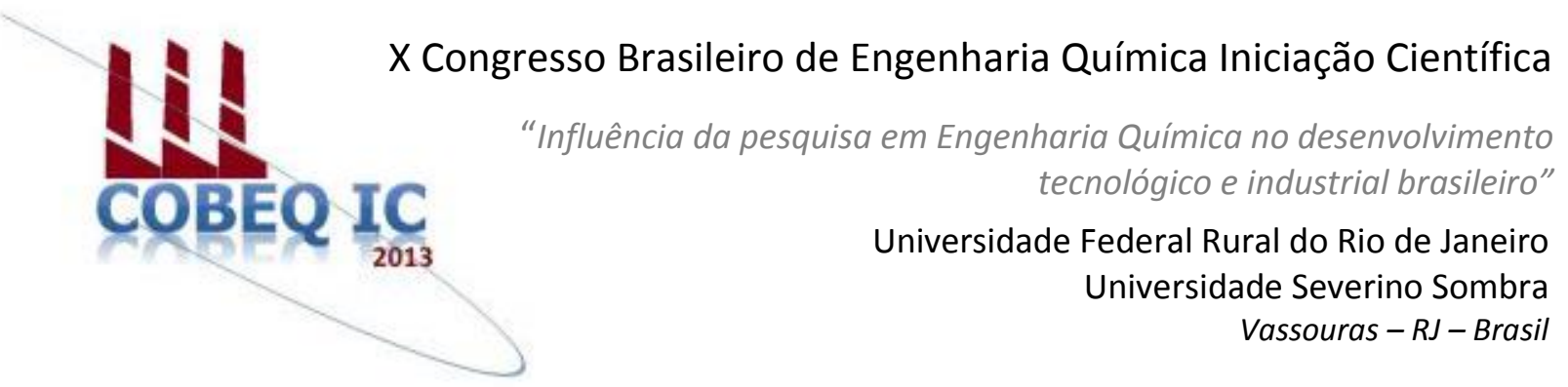

\title{
UTILIZAÇÃo DE FONTES ALTERNATIVAS PARA PRODUÇÃO DE ZEÓLITA NaX E POSTERIOR CARACTERIZAÇÃO
}

\author{
KUWABARA ${ }^{1}$, C. H. M.; VERGENNES ${ }^{1}$, Â. K. de;. SCALIANTE ${ }^{2}$, M. H. N. O.; \\ FERNANDES-MACHADO ${ }^{3}$, N. R. C. \\ ${ }^{1}$ Aluno do DEQ/UEM ${ }^{2}$ Professora Orientadora do DEQ/UEM \\ ${ }^{3}$ Professora Co-orientadora do DEQ/UEM \\ Departamento de Engenharia Química - Universidade Estadual de Maringá \\ Endereço - UEM, Avenida Colombo, N 5790 - Maringá, PR - CEP 87020-900 \\ e-mail: mara@deq.uem.br
}

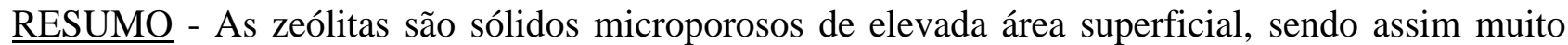
estudadas em diversas áreas de pesquisa, como a da catálise, de processos de adsorção, de troca iônica, entre outros, possibilitando uma vasta aplicação industrial em processos de craqueamento catalítico, purificação de efluentes e gases industriais, etc. O presente trabalho teve como objetivo principal realizar a síntese da zeólita $\mathrm{NaX}$, a sua caracterização e a análise de alguns parâmetros que poderiam influenciar no produto de síntese. Para obtenção da zeólita, partiu-se da metodologia de síntese a partir de condições hidrotérmicas convencionais e do método de fusão alcalina seguida de envelhecimento, utilizando-se como fontes de alumínio e silício a boemita e o aerosil, respectivamente. Os produtos obtidos foram caracterizados pela difração de raios X, espectroscopia de infravermelho e pela microscopia eletrônica de varredura. Pôde-se concluir que no processo de síntese hidrotérmica convencional, a estrutura cristalina final a ser formada depende fortemente dos parâmetros de síntese adotados, e tal influência foi verificada pelo método de difração de raios X. O método de fusão alcalina seguida de envelhecimento mostrou-se a melhor opção para síntese da zeólita $\mathrm{NaX}$, pois os produtos de sua síntese demonstraram uma maior cristalinidade e pureza nas fases formadas.
\end{abstract}

Palavras chave: síntese, cinética, adsorção.

\section{INTRODUÇÃO}

As zeólitas são aluminossilicatos hidratados, que possuem em sua composição cristalina metais alcalinos e/ou metais alcalinos terrosos como cátions de compensação. São sólidos microporosos com uma elevada área superficial, o que os proporciona características catalíticas, de adsorção e de troca iônica, havendo inúmeras aplicações no meio industrial, como na purificação de efluentes e gases industriais, na separação de compostos, no craqueamento catalítico, na redução da dureza de águas industriais, etc.

Devido a sua estrutura porosa e as propriedades de seletividade, as zeólitas foram consideradas como "peneiras moleculares" (McBAIN, 1932 in LUNA \& SCHUCHARDT, 2001). Devido ao fato das 
zeólitas naturais apresentarem impurezas em sua constituição e muitas vezes possuírem composições diferentes em um mesmo material retirado de um depósito de minerais, observou-se a necessidade da criação de técnicas para síntese de zeólitas que poderiam apresentar um grau de pureza elevado.

O estudo da síntese de zeólitas é um ramo abrangente e em evolução, devido ao fato de que a maioria das informações que se possui sobre os métodos de síntese provém de experimentos com tentativas e erros. Busca-se encontrar matérias-primas de síntese que possam originar estruturas cristalinas zeolíticas de elevada pureza, e que possam manter as mesmas propriedades, ou até mesmo, possam apresentar propriedades otimizadas em relação às zeólitas naturais.

\section{METODOLOGIA}

Para a síntese da zeólita $\mathrm{NaX}$ por métodos hidrotérmicos convencionais, utilizou-se uma adaptação da técnica de síntese hidrotérmica convencional, na qual o procedimento é realizado em um único recipiente de acordo com Petkiwicz (PETKIWICZ, 2009).

Para fonte de alumínio e silício, optou-se em utilizar a boemita, oriunda do método solgel e o aerosil, respectivamente. Utilizou-se ainda água deionizada e o hidróxido de sódio como fonte de cátions de compensação e agente complexante.

Inicialmente dissolveu-se todo hidróxido de sódio em água em um reator de teflon, e adicionou-se a fonte de alumínio. Após a solução atingir a temperatura ambiente, adicionou-se lentamente e com agitação, a fonte de silício. Com a formação de um gel com consistência aparentemente homogênea, aqueceu-se tal solução reacional até a temperatura aproximada de $70^{\circ} \mathrm{C}$, e este permaneceu nesta temperatura, sob agitação, por $1 \mathrm{~h}$ (MORAES, 2004).

O gel obtido foi deixado para envelhecimento à temperatura e pressão ambiente, e sem agitação, sendo analisado o período de envelhecimento como parâmetro de síntese.

Após o período de envelhecimento, o gel foi colocado em uma estufa com aeração a temperatura de $100^{\circ} \mathrm{C}$ para a etapa de cristalização, em diferentes tempos de cristalização. Com o término do período de cristalização, os produtos obtidos foram lavados com água deionizada e filtrados, para que se atingisse um material com $\mathrm{pH}$ aproximadamente neutro.

Os materiais lavados e filtrados foram colocados para secagem na estufa à temperatura de $100^{\circ} \mathrm{C}$ por um intervalo de 24 h. Após tal procedimento, foram triturados e peneirados os materiais secos para obtenção do produto na forma de pó, das quais foram realizadas as análises para identificação das fases zeolíticas e não-zeolíticas que poderiam ter sido formadas, por meio do método de difração de raios X. Para tal análise, utilizouse do difratômetro D8 ADVANCE da marca Bruker, com radiação $\mathrm{K} \omega$ do cobre, tensão de $40 \mathrm{KV}$, corrente de $40 \mathrm{~mA}$, tamanho do passo de $0,009^{\circ}$ e tempo por passo de $1 \mathrm{~s}$.

Os produtos obtidos que apresentaram a formação da estrutura zeolítica $\mathrm{NaX}$ foram analisados por microscopia eletrônica de varredura e espectroscopia no infravermelho.

A análise de microscopia de infravermelho foi realizada no equipamento da marca Shimadzu, modelo SS-550, caracterizando a morfologia das estruturas zeolíticas formadas.

A análise de espectroscopia no infravermelho foi realizada no equipamento Vertex 70 da Bruker, utilizando os seguintes parâmetros:

- Número de varredura: 100;

- Resolução: 4 cm ${ }^{-1}$

- Intervalo espectral: Infravermelho médio de $400-4000 \mathrm{~cm}^{-1}$;

- Amostras pastilhadas com $\mathrm{KBr}$ para medida de transmitânicia.

Posteriormente, realizou-se a síntese de zeólita $\mathrm{NaX}$ partindo-se da metodologia de síntese por fusão alcalina seguida de envelhecimento, da qual se obteram zeólitas de maior cristalinidade e pureza de fases. Tal método consistiu em calcinar toda mistura sólida de síntese (aerosil, boemita, hidróxido de sódio) a $350^{\circ} \mathrm{C}$ em uma mufla por $2 \mathrm{~h}$ em reator de teflon. Após o resfriamento da mistura fundida, foi adicionada água desionizada, e a mistura foi agitada por $3 \mathrm{~h}$ em temperatura e pressão ambiente. $\mathrm{O}$ gel 
formado foi envelhecido por 24h, sem agitação, a temperatura ambiente e, em seguida, foi cristalizado em estufa a $100^{\circ} \mathrm{C}$, sem agitação, por $3 \mathrm{~h}$. O produto obtido foi filtrado, lavado com água desionizada e seco em estufa a $100^{\circ} \mathrm{C}$ por $24 \mathrm{~h}$.

$\mathrm{O}$ produto de síntese obtido pelo método de fusão alcalina seguida de envelhecimento foi caracterizado pelas análises de difração e raios $X$, microscopia eletrônica de varredura e espectroscopia no infravermelho como realizados com os produtos da síntese hidrotérmica convencional.

\section{RESULTADOS}

\section{Síntese Hidrotérmica Convencional}

Os parâmetros analisados para este método foram: tempo de envelhecimento, tempo de cristalização e composição da mistura reacional. Para tanto, separaram-se as sínteses realizadas individualmente com o intuito de analisar tais fatores. A síntese 1 destinou-se a análise do tempo de envelhecimento, a síntese 2 para a análise do tempo de cristalização e a síntese 3 para a análise da composição da mistura reacional.

Tempo de Envelhecimento: Na síntese 1, foi adotada uma composição molar da mistura reacional de $1 \mathrm{Al}_{2} \mathrm{O}_{3} \cdot 3 \mathrm{SiO}_{2} \cdot 4,2 \mathrm{Na}_{2} \mathrm{O} \cdot 180,6 \mathrm{H}_{2} \mathrm{O}$ (BRECK, 1984), utilizando-se de boemita previamente sintetizada a partir de precipitação de solução de cloreto de alumínio por hidróxido de amônio. Submeteram-se as amostras a um período de envelhecimento variável de $9 \mathrm{~h}$ e $15 \mathrm{~h}$, e a um período de cristalização de 3 h. Pode-se verificar que não houve a formação da estrutura faujasita em nenhum dos tempos de envelhecimento testados. Os difratogramas da análise de difração de raios $\mathrm{X}$ mostram este fato, conforme mostram as Figuras 1 e 2, indicando que os picos de intensidade das amostras da síntese 1 permanecem sem quase nenhuma alteração, evidenciando que a fase formada, no caso em maior composição a fase estável hidroxissodalita, não se alterou com a variação do tempo de envelhecimento.

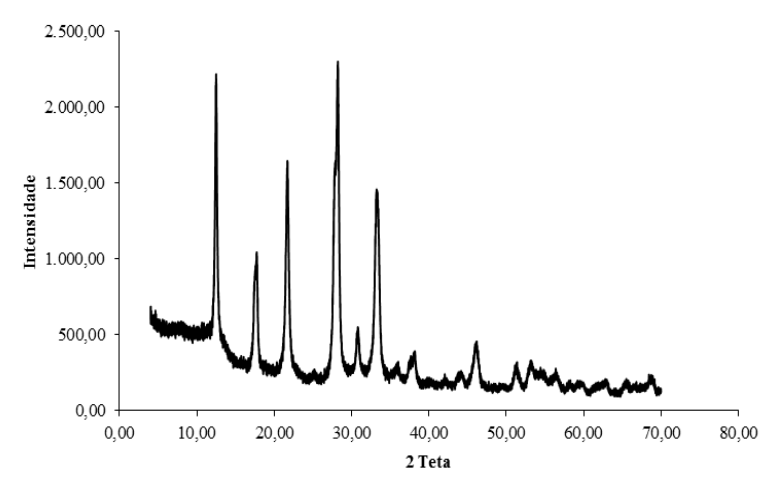

Figura 1 - Difratograma da síntese 1 para $9 \mathrm{~h}$ de envelhecimento.

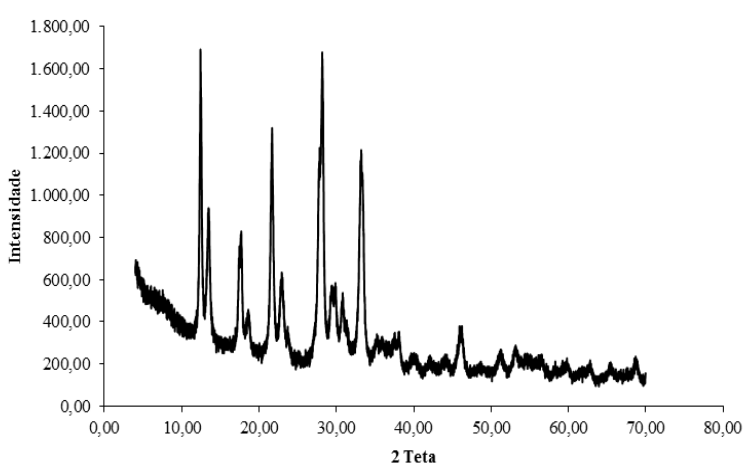

Figura 2 - Difratograma da síntese 1 para $15 \mathrm{~h}$ de envelhecimento.

Tempo de Cristalização: Para a síntese 2, adotou-se a mesma composição molar da mistura reacional da síntese 1 , mas com um período de envelhecimento fixo de $10 \mathrm{~h}$, e um período de cristalização variável de $3 \mathrm{~h}, 6 \mathrm{~h}, 9 \mathrm{~h}$ e 11h. O tempo de envelhecimento foi fixado em $10 \mathrm{~h}$, devido ao fato de que na síntese 1 pode-se observar que a variação no período de envelhecimento não ocasionou uma alteração significativa na estrutura zeolítica produzida, conforme os difratogramas da síntese 1 . Podese avaliar por meio das análises de difração de raios $X$ que o aumento no tempo de cristalização favoreceu a formação de estruturas zeolíticas mais estáveis, como a hidroxissodalita, e que em contrapartida, as fases denominadas metaestáveis, no caso a zeólita $\mathrm{NaX}$, diminuíram a sua porcentagem na estrutura zeolítica. A Figura 3 mostra os difratogramas. Nota-se agora, o pico próximo a 2 teta igual a seis, característico da zeólita $\mathrm{NaX}$. No entanto, o aumento do tempo de cristalização reduziu a quantidade de zeólita 
NaX formada, e o melhor resultado obtido foi com três horas de cristalização.
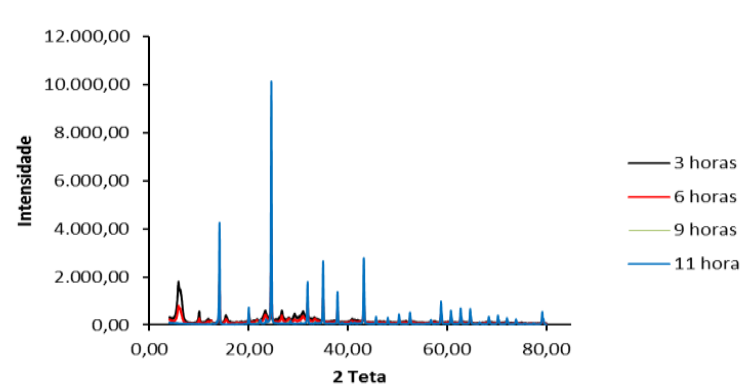

Figura 3 - Difratograma da síntese 2 para $3 \mathrm{~h}, 6 \mathrm{~h}, 9 \mathrm{~h}$ e $11 \mathrm{~h}$ de cristalização.

Pelo difratograma da Figura 3 observa-se que os picos de intensidades característicos da zeólita $\mathrm{NaX}$ tendem a diminuir, enquanto que os picos da fase mais estável, a hidroxissodalita, tornam-se mais acentuados. Isto evidencia que a regra de Ostwald sobre transformações sucessivas é aplicada a síntese de zeólitas. Ela indica que a primeira espécie produzida pode ser progressivamente consumida e substituída por uma segunda espécie mais estável, que por sua vez pode conduzir a uma terceira ainda mais estável e assim sucessivamente até que apareça a fase termodinamicamente estável.

Composição da Mistura Reacional: Na síntese 3 foi adotada uma composição molar da mistura reacional de $1 \mathrm{Al}_{2} \mathrm{O}_{3} .3 \mathrm{SiO}_{2} .3,6 \mathrm{Na}_{2} \mathrm{O} .144 \mathrm{H}_{2} \mathrm{O}$ proposta por (WEITKAMP e PUPPE, 1999), em que se utilizou de boemita previamente sintetizada, submetendo-se as amostras a um período de envelhecimento de $10 \mathrm{~h}$ e a um período de cristalização de $3 \mathrm{~h}$ e $6 \mathrm{~h}$. Por meio da análise de difração de raios $X$ pode-se analisar que a diminuição de água na composição da mistura reacional, e o aumento na alcalinidade do meio, levaram a formação direta de estruturas mais estáveis, no caso a hidroxissodalita, não havendo a formação de fases metaestáveis durante o processo. Isto é observado por meio dos difratogramas das Figuras 4 e 5.

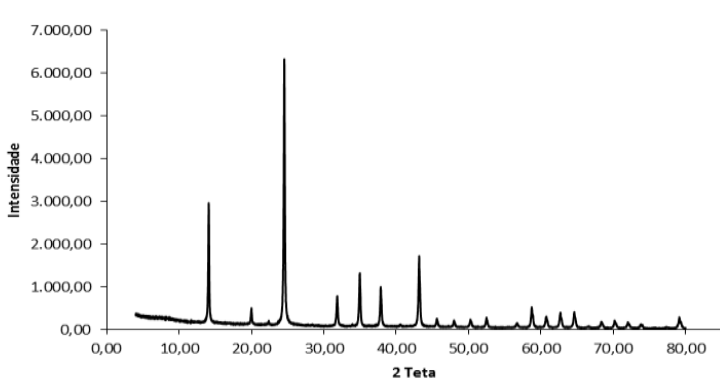

Figura 4 - Difratograma da síntese 3 para 3 h de cristalização.

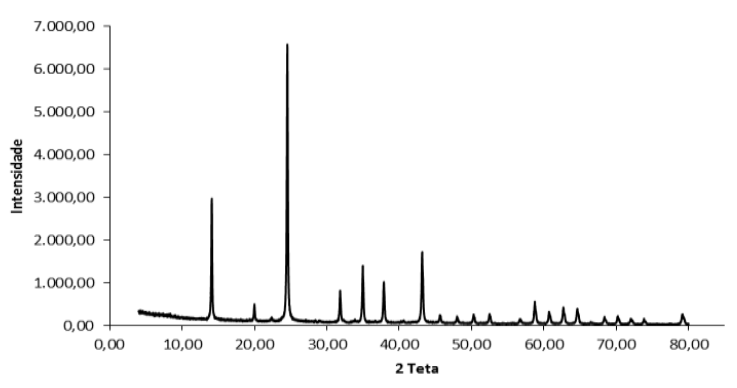

\section{Figura 5 - Difratograma da síntese 3 para 6 h de cristalização.}

As amostras que apresentaram a formação de estrutura faujasítica, mesmo que em pequena porcentagem de fase, no caso a síntese 2, foram analisadas por microscopia eletrônica de varredura, para uma análise morfológica e das células unitárias do material sintetizado. As micrografias desta análise são mostradas nas Figura 6.

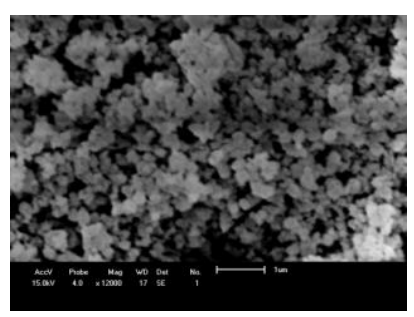

(a)

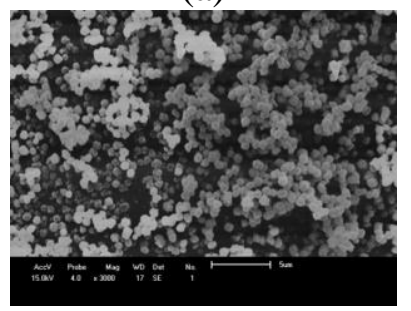

(b)

Figura 6 - Microscopia eletrônica de varredura da amostra da síntese 2 submetida a (a) 3 horas de cristalização (b) 11 horas de cristalização. 
As micrografias apresentadas na Figura 6 (a) e 6 (b) mostram que a nucleação e o crescimento dos cristais zeolíticos ocorrem simultaneamente promovendo a grande distribuição do tamanho das partículas. Estas também permitem visualizar as estruturas cúbicas dos cristais, que são característicos das estruturas faujasíticas.

A análise de espectroscopia no infravermelho foi realizada nas amostras de 3 horas e 11 horas de cristalização da síntese 2, para observar a diferença entre as bandas do infravermelho nas estrutura faujasítica formada com 3 horas e a da hidroxissodalita formada com $11 \mathrm{~h}$. Elas são apresentadas nas Figuras 7 e 8.

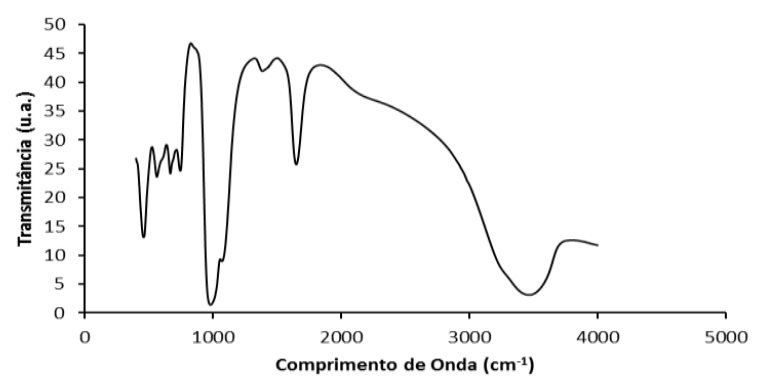

Figura 7 - Espectroscopia no

Infravermelho da amostra da síntese 2 submetida à 3 horas de cristalização.

A Figura 7 demonstra bandas características da zeólita $\mathrm{NaX}$, conforme os dados fornecidos pela literatura.

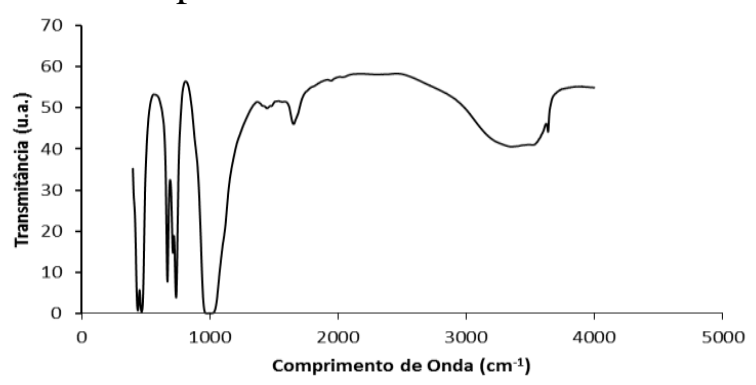

Figura 8 - Espectroscopia no

Infravermelho da amostra da síntese 2 submetida à 11 horas de cristalização.

Pela Figura 8 é possível observar o aumento nas bandas características da hidroxissodalita, conforme os dados fornecidos pela literatura.

Síntese por Fusão Alcalina seguida de envelhecimento
Para tal síntese, denominada como síntese 4 , adotou-se a composição molar da mistura reacional de $1 \mathrm{Al}_{2} \mathrm{O}_{3} .3 \mathrm{SiO}_{2} .5,7 \mathrm{Na}_{2} \mathrm{O} .288 \mathrm{H}_{2} \mathrm{O}$ proposta por (LUCAS et al., 1992), com um período de envelhecimento de $24 \mathrm{~h}$, e um período de cristalização de $3 \mathrm{~h}$ apenas. Pode-se avaliar por meio da análise de difração de raios $X$ que houve a formação de um material zeolítico extremamente cristalino, evidenciado pela elevada intensidade dos picos nos valores de 2 Teta característicos da zeólita $\mathrm{NaX}$. A Figura 9 mostra o difratograma. Nota-se que o pico próximo a 2 teta igual a seis, característico da zeólita $\mathrm{NaX}$ possui uma elevada intensidade. É possível observar também a formação de zeólita $\mathrm{NaA}$ na estrutura, mas em pequena proporção em relação a zeólita $\mathrm{NaX}$.

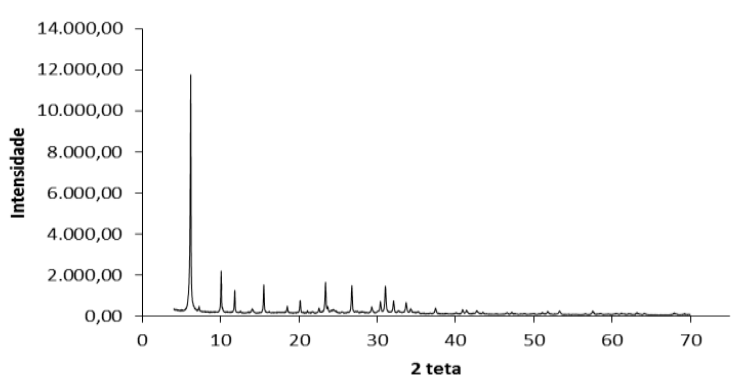

Fugira 9 - Difratograma da síntese 4.

A partir da análise de difração de raios $\mathrm{X}$, realizou-se a análise de microscopia eletrônica de varredura para verificação da morfologia da estrutura zeolítica formada. Tal análise é representada na Figura 10 abaixo.

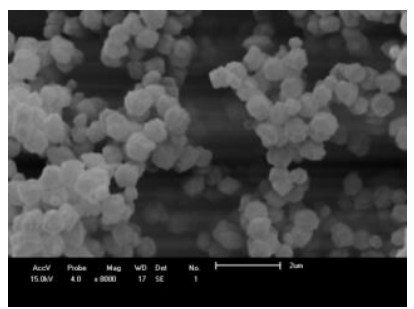

\section{Fugira 10 - Micrografia da amostra da síntese 4.}

A micrografia apresentada na Figura 10 permite visualizar as estruturas cúbicas dos cristais, que são característicos das estruturas faujasíticas, bem como sua boa distribuição e distinção. 


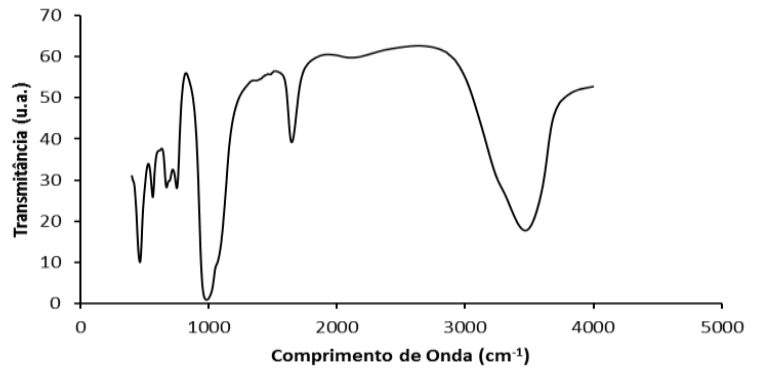

Figura 11 - Espectroscopia no Infravermelho da amostra da síntese 4.

A Figura 11 denota claramente as bandas características da zeólita $\mathrm{NaX}$, e com um pouco de aparecimento das bandas da zeólita $\mathrm{NaA}$.

\section{CONCLUSÃO}

Os resultados das análises de difração de raios X mostraram a ocorrência de zeólita $\mathrm{NaX}$ na síntese 2 pelo método de síntese hidrotérmica convencional, podendo ser visualizada por meio dos picos característicos da faujasita nos difratogramas analisados. A formação da fase estável hidroxissodalita também ocorre em todos os procedimentos, tendo em vista que os materiais de partida são extremamente reativos, no caso a boemita e o aerosil, levando a uma maior e mais rápida nucleação das partículas do gel de mistura reacional em um pequeno intervalo de tempo.

Ficou evidente que para obtenção da zeólita $\mathrm{NaX}$, o método de síntese com fusão alcalina seguida de envelhecimento se mostrou mais adequada para obtenção de uma estrutura mais cristalina. As análises de difração de raios $\mathrm{X}$, microscopia eletrônica de varredura e espectroscopia no infravermelho demosntraram a formação de uma estrutura extremamente cristalina, a morfologia faujasítica e as bandas características da zeólita $\mathrm{NaX}$, respectivamente.

\section{REFERÊNCIAS}

BRECK, D. W., 1984. Zeolite Molecular Sieves. $2^{\mathrm{a}}$ ed., New York, John Wiley \& Sons.

LUCAS, A., UGUINA, M. A., COVIÁN, I., RODRÍGUEZ, L., 1992, "Synthesis of 13X zeolite from Calcined kaolins and
Sodium silicate for use in Detergents, Industrial and Engineering Chemistry Research”, v. 31, pp. 2134-2140.

LUNA, F. A.; UGUINA, M. A.; COVIÁN, I. e RODRIGUEZ, L. 1992, "Synthesis of 13X Zeolite from calcined kaolins and sodium silicate for use in detergents", Industrial Eng. Chem. Research, v. 31, n. 9, p. 2134-2140.

MORAES, E. P., 2004, Síntese de zeólita a partir de matéria-prima nacional natural. Tese de Doutorado, DEQ/UEM, Maringá, PR, Brasil.

PETKOWICZ, D. I., Zeólitas sintetizadas com fontes alternativas de silício e alumínio.Aplicação em fotocatálise. Dissertação de mestrado. Programa de Pós-graduação Ciência dos Materiais, Universidade do Rio Grande do Sul, Porto Alegre, 2009.

WEITKAMP, J., PUPPE, L., 1999. Catalysis and Zeolites Fundamentals and Applications. $1^{\text {a }}$ ed., Germany, SpringVerlag Berlin Heidelberg. 